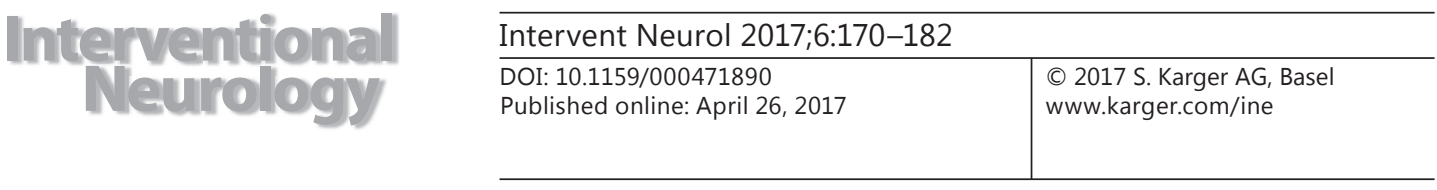

\title{
Safety and Efficacy of Low-Profile, Self-Expandable Stents for Treatment of Intracranial Aneurysms: Initial and Midterm Results - A Systematic Review and Meta-Analysis
}

\author{
Su-Yeon Park ${ }^{b}$ Jae-Sang Oh ${ }^{a}$ Hyuk-Jin Oh $^{a}$ Seok-Mann Yoon ${ }^{a}$ Hack-Gun Bae ${ }^{a}$ \\ Departments of a Neurosurgery and ${ }^{\mathrm{b}}$ Statistics, Soonchunhyang University Hospital Cheonan, \\ Cheonan, Republic of Korea
}

\section{Keywords}

Intracranial aneurysm · Low-profile stent · Recurrence · Stent-assisted coil ·

Thromboembolism

\begin{abstract}
Low-profile stents seem to be associated with a higher incidence of thromboembolic events compared with preexisting stents. We conducted a systematic review of 11 eligible reports and a meta-analysis of 7 reports with respect to the clinical efficacy and safety of low-profile stents. There were 217 intracranial aneurysms reported; $22 \%$ were ruptured aneurysms. In all, $72 \%$ were treated using single stenting, $19 \%$ were treated using overlapping stenting, and $6 \%$ were treated using balloon angioplasty followed by stenting; $3 \%$ were used to assess the flow diverter effect in a dissecting aneurysm or were treated using unexpected subtotal coil packing. On immediate postprocedural angiographic results, Raymond class I and II obliteration was obtained in $87 \%$ of the aneurysms. On angiographic results at 3-6 months, Raymond class I and II obliteration or stability was obtained in $79 \%$ of the aneurysms, and Raymond class III obliteration was obtained in $3 \%$ of the aneurysms. The recurrence rate on follow-up of intracranial aneurysms was $6.5 \%$ (5.7\% with LEO Baby and $1.3 \%$ with LVIS Jr). The periprocedural complication rate was $12.4 \%$. Periprocedural thromboembolism occurred in $6.5 \%$ of the cases. The rate of in-stent stenosis on follow-up of intracranial aneurysms was $10 \%$. In the midterm result, the recurrence rate with use of low-profile, self-expandable stents was relatively low compared to that with use of other self-expandable stents. In the meta-analysis comparing LEO Baby with LVIS Jr, the obliteration rate at 6 months was not significantly different, but the periprocedural complication rate was relatively low with LVIS Jr.
\end{abstract}

(C) 2017 S. Karger AG, Basel

Jae-Sang Oh, MD

Department of Neurosurgery, Soonchunhyang University Hospital Cheonan

23-20 Bongmyeong-dong

Cheonan City, Chungcheongnam-do 330-721 (Republic of Korea)

E-Mail metatron1324@ hotmail.com 


\section{Introduction}

The stent-assisted coiling (SAC) technique was developed to treat wide-neck intracranial aneurysms (IAs) and to prevent coil protrusion into the parent artery [1]. SAC can reduce the risk of recanalization of IAs, especially in larger aneurysms, which are known to recur more frequently [2]. Since the first self-expandable stent was developed in 2002 for performing SAC, it has been very useful for treating complex wide-neck aneurysms by providing a scaffold during coiling. For the deployment of self-expandable stents, a 0.021 - to 0.027 -inch microcatheter needs to be used for navigation to the parent artery. If the angle of the parent artery has a slope or a winding path, it is difficult to advance the microcatheter into the parent artery for deployment of the stent. Thus, this maneuver should be performed by an experienced endovascular neurosurgeon using the exchange technique.

Low-profile, self-expandable stents (LEO Baby and LVIS Jr) were developed in 2011, and these stents can be delivered through a 0.0165-inch microcatheter. By using a smaller diameter of the microcatheter, catheterization and navigation to a small-sized artery become easier. There are 2 stents (LEO Baby and LVIS Jr) that have a self-expandable and low profile. It is recommended to use these stents with the jailing technique before stent deployment.

Recently, low-profile, self-expandable stents have been used widely and are regarded as a safe and useful device for stent-assisted coil embolization. However, they seem to be associated with a higher incidence of thromboembolic events compared with preexisting stents. Here, we present a systematic literature review of the applications, safety, and clinical efficacy of this therapy.

\section{Materials and Methods}

We used multiple comprehensive databases to find literature studying the safety and efficacy of lowprofile, self-expandable stents for the treatment of IAs. This study is based on the Cochrane Review Methods ${ }^{1}$. We searched MEDLINE, Embase, the Cochrane Central Register of Controlled Trials (CENTRAL), Web of Science, and Scopus on February 23, 2016. We placed no restrictions on language or year of publication in our search.

Data Source and Literature Source

The following keywords and MeSH terms were searched in MEDLINE: "cerebral" or "intracranial" or "brain" or "aneurysm" or "anterior communicating" or "posterior communicating" or "basilar" or "pericallosal" or "subarachnoid hemorrhage" and "stent" or "coil" or "neuroendovascular" or "neurointervention" or "stents" or "thromboembolism." The search strategies were adapted to the other databases based on the MEDLINE strategy. After the initial electronic search, we hand-searched further relevant articles and bibliographies from the studies identified. Articles identified were assessed individually for inclusion.

\section{Study Selection}

Study inclusion was independently decided on by 2 reviewers based on the selection criteria. Study selection was performed through 2 levels of screening: at the first level, we screened the titles and abstracts of the identified studies; at the second level, we screened the full text. Studies were included in our metaanalysis if they (1) described the clinical and angiographic outcomes of low-profile, self-expandable stents (LEO Baby or LVIS Jr) when used alone or in combination with other stents, (2) described a case of SAC using low-profile, self-expandable stents (LEO Baby or LVIS Jr), and (3) were published in the English language. LVIS stents or LEO stents are not low-profile stents; hence, they were excluded.

${ }^{1}$ Green S, Higgins JPT: Cochrane Handbook for Systematic Reviews of Interventions version 5.1.0. See http://training.cochrane.org/handbook. 


\section{Data Extraction}

Two reviewers independently extracted the data from each study using a predefined data extraction form. Any disagreement unresolved by discussion was put under the review of a third author.

The following variables were extracted from the studies: (1) citation information (author and publication year); (2) baseline patient characteristics (total sample size and number of patients and IAs that were ruptured or unruptured, location of IAs, and mean diameter of the parent artery in which the stent was deployed); (3) method of stent deployment (single, overlapping stenting, balloon angioplasty followed by stenting, and flow diverter); (4) aneurysm obliteration rates (in the immediate period and the follow-up period of 3-6 months); (5) recurrences; (6) complications (overall complications, thromboembolic events, technical complications, and in-stent stenosis); and (7) clinical outcomes and procedure-related morbidity.

The location of the aneurysm was classified according to anterior and posterior circulation. Stent deployment was performed using various methods with single stenting, dual or overlapping stenting (X-, Y-, and T-stenting), first balloon angioplasty followed by stenting, and telescopic stenting for a flow diverter-like effect. The aneurysm obliteration rate was reported in the angiographic outcome immediately and 3-6 months after SAC, including categories such as "complete occlusion," "neck remnant," and "partial occlusion" or Raymond class (I, complete obliteration; II, neck remnant; III, partial occlusion) [3]. Recurrence was described as recanalization (deterioration of the Raymond class) or need for retreatment. Complications included periprocedural and technical problems. Periprocedural thromboembolism was described as a thromboembolic event during SAC. Postprocedural thromboembolism was excluded from this study. In-stent stenosis was described in the articles as "stenosis" and "in-stent thrombosis" during the follow-up period. Clinical outcomes were reported in various ways using the modified Rankin Scale (mRS) or as a good/poor outcome. We categorized a "good outcome" as an mRS score of $0-2$. If the above variables were not mentioned in the studies, we asked for the data via e-mail.

\section{Statistical Analysis}

The main outcomes of our review were procedure-related complications, thromboembolism, and technical complications. The other outcomes of our review were as follows: (1) obliteration rate (immediately and 3-6 months after SAC); (2) recurrence of IAs and in-stent stenosis; and (3) clinical outcomes as expressed using the mRS and procedure-related morbidity. They are expressed as a rate (\%). We conducted planned subgroup analyses to compare the rate of immediate obliteration, obliteration 3-6 months after SAC, recurrence, periprocedural complications, periprocedural thromboembolism, technical complications, in-stent stenosis, good mRS scores, and procedure-related morbidity between the LEO Baby and the LVIS Jr stent.

Meta-analyses of 3 outcomes (obliteration at 6 months, periprocedural complications, and technical complications) were conducted using a random-effects model [4], and subgroup analysis was performed with the type of stent. To calculate summary statistics for each outcome measure, zero cell entries could be problematic; thus, the value of 0.5 was added to solve this problem. The results are given as proportion rates with 95\% confidence intervals (CIs). For all tests, heterogeneity testing was performed using Cochran's $Q$ test, and significant heterogeneity was observed at $p<0.1$. Also, we reported heterogeneity with $I^{2}$, which describes the percentage of total variation across trials due to heterogeneity rather than chance [5]. Egger's test was used to detect publication bias. For post hoc analysis, noninferiority testing was performed to determine whether the LVIS Jr stent is not worse than the LEO Baby stent within a noninferiority margin (NI margin). We used the metafor package in R (version 3.1.2) and SPSS (version 14.0; SPSS Inc., Chicago, IL, USA) statistical software.

\section{Results}

\section{Identification of Studies}

Searching of the databases yielded 8,769 articles (Fig. 1). Of these, 8,743 publications were excluded as the title and abstract clearly indicated that they did not fulfill the selection criteria. Of the remaining 26 articles, we obtained the full text, and on subsequent scrutiny of these articles, we identified 11 potentially relevant studies; 15 publications were excluded as they were not about low-profile stents or were duplicate publications. Although 2 publications were about low-profile stents, one publication was not a full text and the other was a 
Park et al.: Safety and Efficacy of Low-Profile, Self-Expandable Stents for Treatment of Intracranial Aneurysms: Initial and Midterm Results

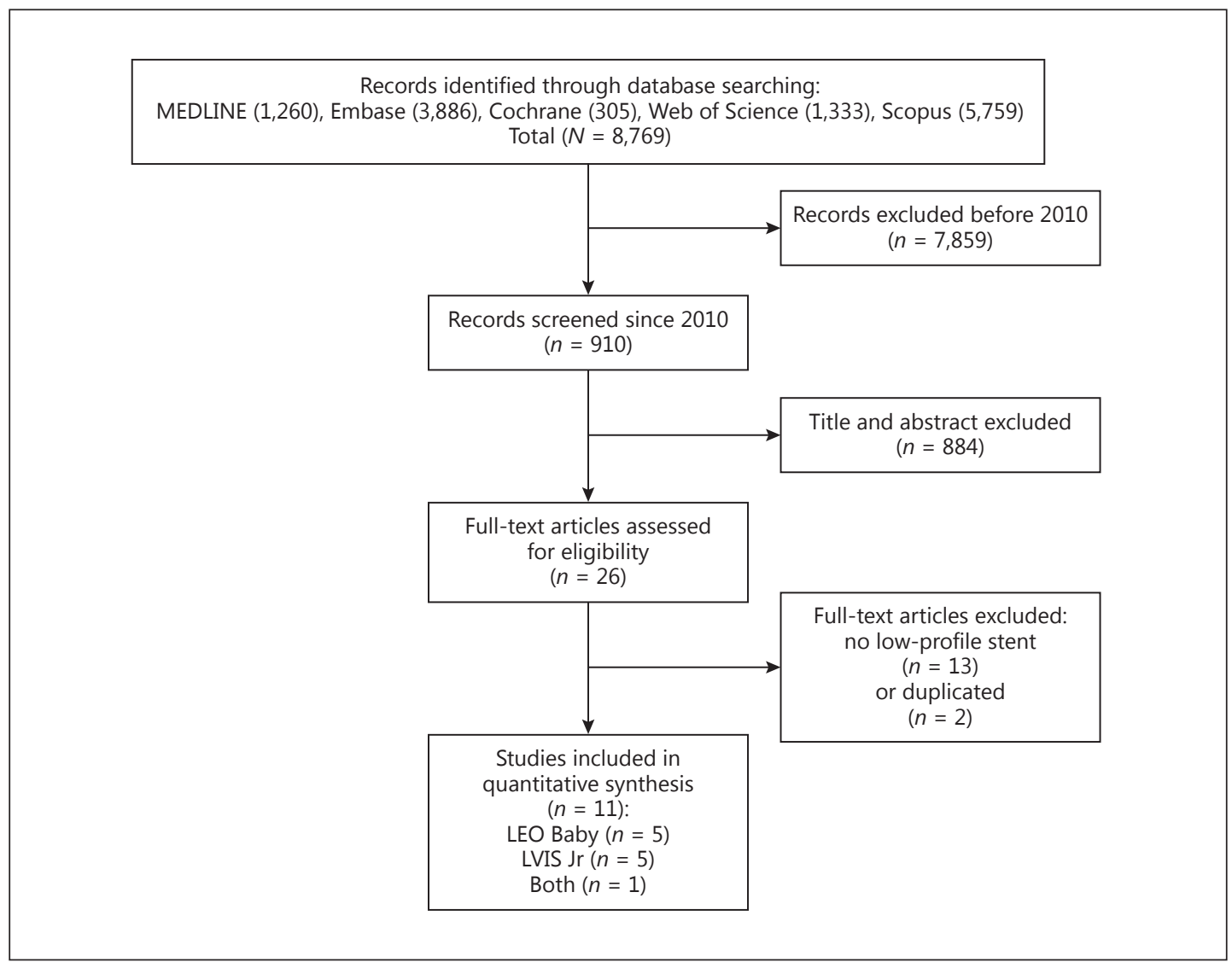

Fig. 1. Flowchart of study selection for low-profile, self-expandable stents.

study in combination with an LVIS stent. Therefore, the total number of studies included in the review was 11 (Fig. 1). In the meta-analysis, case reports or combined studies were excluded. Thus, 3 publications on LEO Baby and 4 publications on LVIS Jr were included.

\section{Study Characteristics and Patient Populations}

Table 1 shows the baseline characteristics of 11 publications on SAC using low-profile stents. Results for LEO Baby stents were reported in 5 publications and results for LVIS Jr stents were reported in 5 publications. One study reported results on 6 cases of SAC using 5 LEO Baby stents and 1 LVIS Jr stent. A total of 217 IAs were included, and 48 (22\%) of the IAs were ruptured; 185 (85\%) of the IAs were located in the anterior circulation. With respect to the method of stent deployment, 157 (72\%) of the IAs were treated using single stenting and 42 (19\%) were treated using overlapping stenting (Y-, T-, and X-stenting). Based on the characteristics of the low-profile stents, 4 IAs (located in the middle cerebral artery [MCA], basilar artery, and posterior and anterior communicating arteries) were treated with balloon angioplasty followed by stenting using LVIS Jr stents, and 8 IAs (located in 1 anterior communicating artery, in 1 callosomarginal artery, and in 6 MCAs) were treated with balloon angioplasty followed by stenting using LEO Baby stents [6, 7]. Flow diverter effects of low-profile stents were described when immediate contrast medium stagnation was visualized with only stenting or residual filling after SAC had disappeared during the follow-up period. Six IAs (5 with LEO Baby stents and 1 with an LVIS Jr stent) were treated using telescopic stent mono- 


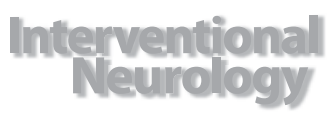

Intervent Neurol 2017,6:170-182

Park et al:: Safety and Efficacy of Low-Profile, Self-Expandable Stents for Treatment of Intracranial Aneurysms: Initial and Midterm Results

Table 1. Characteristics of the aneurysms treated with low-profile, self-expandable stents in 11 eligible studies

\begin{tabular}{|c|c|c|c|c|c|c|c|c|c|c|c|}
\hline \multirow[t]{2}{*}{ Study [Ref.] } & \multirow[t]{2}{*}{ Stent } & \multirow{2}{*}{$\begin{array}{l}\text { IAs, } \\
n\end{array}$} & \multirow{2}{*}{$\begin{array}{l}\text { SAH, } \\
n\end{array}$} & \multirow{2}{*}{$\begin{array}{l}\text { UIA, } \\
n\end{array}$} & \multirow{2}{*}{$\begin{array}{l}\text { Vessel diameter } \\
\text { (mean/range), mm }\end{array}$} & \multicolumn{2}{|l|}{ Location, $n$} & \multicolumn{4}{|c|}{ Method of stent deployment, $n$} \\
\hline & & & & & & $\begin{array}{l}\text { anterior } \\
\text { circulation }\end{array}$ & $\begin{array}{l}\text { posterior } \\
\text { circulation }\end{array}$ & $\begin{array}{l}\text { single } \\
\text { stent }\end{array}$ & $\begin{array}{l}\text { over } \\
\text { lapping } \\
\text { stenting }\end{array}$ & $\begin{array}{l}\text { balloon } \\
\text { followed } \\
\text { by SAC }\end{array}$ & $\begin{array}{l}\text { flow } \\
\text { diverter }\end{array}$ \\
\hline Akmangit [9] & LEO Baby & 12 & 3 & 9 & - & 9 & 3 & 3 & 6 & 0 & 3 \\
\hline Aydin [10] & LEO Baby & 80 & 11 & 69 & 3.5 & 72 & 8 & 66 & 14 & 0 & 0 \\
\hline Dall'olio [8] & LEO Baby & 1 & 0 & 1 & - & 1 & 0 & 1 & 0 & 0 & 0 \\
\hline Cohen [11] & LEO Baby & 1 & 1 & 0 & $0.75-2.1$ & 1 & 0 & 0 & 1 & 0 & 0 \\
\hline Machi [6] & LEO Baby & 29 & 1 & 28 & $1.5-3.1$ & 26 & 3 & 18 & 1 & 8 & 2 (1: blister) \\
\hline Behme [12] & LVIS Jr & 34 & 12 & 22 & $2.2(1.1-2.5)$ & 26 & 8 & 23 & 10 & 0 & 1 \\
\hline Conrad [18] & LVIS Jr & 2 & 0 & 2 & - & 0 & 2 & 1 & 1 & 0 & 0 \\
\hline Feng1 (ACA) [14] & LVIS Jr & 12 & 7 & 5 & $2.16(1.63-2.57)$ & 12 & 0 & 12 & 0 & 0 & 0 \\
\hline Feng2 (MCA) [13] & LVIS Jr & 18 & 5 & 13 & $1.8-3.2$ & 18 & 0 & 18 & 0 & 0 & 0 \\
\hline Möhlenbruch [7] & LVIS Jr & 22 & 4 & 18 & $1.6-2.6$ & 16 & 6 & 9 & 9 & 4 & 0 \\
\hline Negrotto [19] & $\begin{array}{l}5 \text { (LEO Baby) } \\
1 \text { (LVIS Jr) }\end{array}$ & 6 & 4 & 2 & $\sim 1.5$ & 4 & 2 & 6 & 0 & 0 & 0 \\
\hline
\end{tabular}

IA, intracranial aneurysm; SAH, subarachnoid hemorrhage; UIA, unruptured intracranial aneurysm; SAC, stent-assisted coil embolization; ACA, anterior cerebral artery; MCA, middle cerebral artery.

therapy for dissecting aneurysms or unexpected subtotal coil packing. Dall'olio et al. [8] reported that successful obliteration of a recanalized giant aneurysm which recurred after surgery and coiling was achieved with a LEO Baby stent. Neointimal in-stent growth or boost endothelialization of a low-profile stent is regarded as the main pathogenesis of flow diverter effects $[6,8]$.

Table 2 shows the results from all 11 publications, and Table 3 shows the comparison data and comparative results between the LEO Baby and the LVIS Jr stent. One publication reported results on the combined use of 2 stents (5 LEO Baby stents and 1 LVIS Jr stent). We could classify the baseline characteristics by obtaining the detailed characteristics via e-mail from the corresponding author (Negrotto).

\section{Obliteration Rate and Recurrence}

Immediate angiographic results were reported in all 11 publications (215 of the 217 IAs; $99 \%$ ), but 2 cases of IA which did not describe immediate results showed intraprocedural thromboembolism within the parent artery (1\%) [6]. On immediate postprocedural angiographic results, Raymond class I and II obliteration was obtained in $87 \%$ of the aneurysms, and Raymond class III obliteration was obtained in $13 \%$ of the aneurysms, including 6 IAs which had a SAC-like flow diverter. The immediate angiographic results for 3 patients who underwent telescopic stenting for flow diverter effects revealed complete occlusion in 1 patient and a remnant neck in 2 patients [9].

An obliteration rate at 3-6 months was reported in most studies (170 IAs; 78\%). On angiographic results at 6 months, Raymond class I and II obliteration was obtained in $77 \%$ of the aneurysms, and Raymond class III was obtained in 1\% of the aneurysms. In 8\% of the 217 IAs, a follow-up result was not reported. It seemed that the angiographic results for the LEO Baby stents were better than those for the LVIS Jr stents (immediately I + II: 93\% for LEO Baby stents), but there were too many missing data for the LVIS Jr stents during follow-up; hence, it was difficult to perform an accurate assessment.

All 11 publications reported on recurrence. The recurrence rate for the total of 217 IAs was 4\% (5.4\% with LEO Baby stents and 1.1\% with LVIS Jr stents), and the recurrence rate for the 189 IAs which excluded the loss-to-follow-up data was $6.5 \%$ (5.7\% with LEO Baby stents and $1.3 \%$ with LVIS Jr stents). The recurrence rate was higher with LEO Baby stents than with LVIS Jr stents. Aydin et al. [10] reported the highest recurrence rate $6.5 \%$ of 80 
Park et al.: Safety and Efficacy of Low-Profile, Self-Expandable Stents for Treatment of Intracranial Aneurysms: Initial and Midterm Results

Table 2. Radiographic outcomes, procedure-related complications, and prognoses of aneurysms treated with low-profile, selfexpandable stents

\begin{tabular}{|c|c|c|c|c|c|c|c|c|c|c|}
\hline \multirow[t]{2}{*}{ Study [Ref.] } & \multicolumn{3}{|l|}{ Obliteration } & \multirow{2}{*}{$\begin{array}{l}\text { Recur- } \\
\text { rence }\end{array}$} & \multirow{2}{*}{$\begin{array}{l}\text { Peri- } \\
\text { procedural } \\
\text { compli- } \\
\text { cations }\end{array}$} & \multirow{2}{*}{$\begin{array}{l}\text { Peri- } \\
\text { procedural } \\
\text { thrombo- } \\
\text { embolism }\end{array}$} & \multirow{2}{*}{$\begin{array}{l}\text { Technical } \\
\text { compli- } \\
\text { cations }\end{array}$} & \multirow{2}{*}{$\begin{array}{l}\text { In-stent } \\
\text { stenosis }\end{array}$} & \multirow{2}{*}{$\begin{array}{l}\text { Good } \\
\text { mRS score } \\
(0,1)\end{array}$} & \multirow{2}{*}{$\begin{array}{l}\text { Procedure- } \\
\text { related } \\
\text { morbidity }\end{array}$} \\
\hline & immediately & $\begin{array}{l}\text { at } \\
3-6 \text { months }\end{array}$ & $\begin{array}{l}\text { at } \\
6 \text { months }\end{array}$ & & & & & & & \\
\hline \multirow[t]{2}{*}{ Akmangit [9] } & I + II: 11 (91) & $\begin{array}{l}\text { I: } 11(91) \\
1^{\mathrm{a}}\end{array}$ & $\begin{array}{l}\mathrm{I}: 11(91) \\
1^{\mathrm{a}}\end{array}$ & $1(9)$ & $2(17)$ & $0(0)$ & $2(17)$ & $0(0)$ & $12(100)$ & $0(0)$ \\
\hline & III: 1 (9) & & & & & & & & & \\
\hline \multirow[t]{4}{*}{ Aydin [10] } & I: 60 (75) & - & I: 66 (82.5) & $5(6.5 \%)$ & $7(8.8)$ & $5(6.3)$ & $2(2.5)$ & $12(15.5)$ & 77 (96.2) & $3(3.8)$ \\
\hline & II: 17 (21.3) & & II: 9 (11.2) & & & & & & & \\
\hline & III: 3 (3.7) & & III: 2 (2.5) & & & & & & & \\
\hline & & & $3^{\mathrm{a}}$ & & & & & & & \\
\hline Dall'olio [8] & II: 1 (100) & I: $1(100)$ & - & $0(0)$ & $0(0)$ & $0(0)$ & $0(0)$ & $0(0)$ & $1(100)$ & $0(0)$ \\
\hline Cohen [11] & I: $1(100)$ & I: $1(100)$ & - & $0(0)$ & $0(0)$ & $0(0)$ & $0(0)$ & $0(0)$ & $1(100)$ & $0(0)$ \\
\hline \multirow[t]{4}{*}{ Machi [6] } & I: $16(55.1)$ & I: 27 (93.1) & I: 26 (89.7) & $1(3.4)$ & $5(17.2)$ & $3(10.3)$ & $2(6.8)$ & $3(10.3)$ & 27 (93.2) & $0(0)$ \\
\hline & II: 8 (27.6) & & III: 1 (3.4) & & & & & & & \\
\hline & III: 3 (10.3) & & $2^{\mathrm{a}}$ & & & & & & & \\
\hline & $\begin{array}{l}\text { Failure: } \\
2(6.9)\end{array}$ & & & & & & & & & \\
\hline \multirow[t]{3}{*}{ Behme [12] } & I: 16 (50.1) & - & Stable: & $1(4)$ & $2(5.8)$ & $2(5.8)$ & $0(0)$ & $2(5.8)$ & $23(67.6)$ & $0(0)$ \\
\hline & II: 5 (14.7) & & 25 (73.5) & & & & & & & \\
\hline & III: 12 (35.2) & & $9^{a}$ & & & & & & & \\
\hline Conrad [18] & I: 2 (100) & I: $2(100)$ & I: 2 (100) & $0(0)$ & $0(0)$ & $0(0)$ & $0(0)$ & $0(0)$ & $2(100)$ & $0(0)$ \\
\hline \multirow{3}{*}{$\begin{array}{l}\text { Feng1 (ACA) } \\
{[14]}\end{array}$} & I: 7 (58.3) & Stable: & - & $0(0)$ & $0(0)$ & $0(0)$ & $0(0)$ & $1(8.3)$ & 11 (91.6) & $0(0)$ \\
\hline & II: 3 (25) & $9(75)$ & & & & & & & & \\
\hline & III: 2 (16.7) & $3^{a}$ & & & & & & & & \\
\hline \multirow{3}{*}{$\begin{array}{l}\text { Feng2 (MCA) } \\
\text { [13] }\end{array}$} & I: 8 (44.4) & I: 12 (66.7) & - & $0(0)$ & $1(5.5)$ & $1(5.5)$ & $0(0)$ & $0(0)$ & 17 (94.4) & $1(5.5)$ \\
\hline & II: 7 (38.9) & II: 3 (16.7) & & & & & & & & \\
\hline & III: 3 (16.7) & III: 3 (16.7) & & & & & & & & \\
\hline \multirow{2}{*}{$\begin{array}{l}\text { Möhlenbruch } \\
\text { [7] }\end{array}$} & I: 16 (73) & & I: 18 (81.8) & $0(0)$ & $7(31.8)$ & $3(13.6)$ & $4(18.2)$ & $1(5)$ & $22(100)$ & $0(0)$ \\
\hline & II: 6 (27) & & II: 4 (18.1) & & & & & & & \\
\hline Negrotto [19] & I: 6 (100) & I: 6 (100) & I: 6 (100) & $0(0)$ & $0(0)$ & $0(0)$ & $0(0)$ & $0(0)$ & $6(100)$ & $0(0)$ \\
\hline
\end{tabular}

Values are $n$ (\%). mRS, modified Rankin Scale; ACA, anterior cerebral artery; MCA, middle cerebral artery. ${ }^{\text {a }}$ Follow-up loss.

IAs) of the 11 publications. There were 4 IAs which required retreatment, and the mean dome size of the IAs in this study was 7.26 $\pm 3.41 \mathrm{~mm}$ (range 3-22).

\section{Complications and Procedure-Related Morbidity}

All publications reported overall complication rates, thromboembolisms, and technical complications. The intraprocedural complication rate was $12.4 \%$ (10.9\% with LEO Baby stents and $11.2 \%$ with LVIS Jr stents). Thromboembolism occurred in $6.3 \%$ of the cases treated with LEO Baby stents and in $6.7 \%$ of the cases treated with LVIS Jr stents. The rate of technical complications was $4.7 \%$ with LEO Baby stents and $4.5 \%$ with LVIS Jr stents. In the studies on LVIS Jr stents, there were no technical complications, except in 1 study. Möhlenbruch et al. [7] reported 4 cases of technical complications with LVIS Jr stents. These included stent migration during horizontal stenting of carotid-T aneurysm, partial stent opening on the basilar artery to P1 (angled) and P1 to SAC (horizontal stenting), and failure to completely open on A1 to A2 for X-stenting. However, these patients had no neurological symptoms after the procedure, and during the follow-up period, they showed stable and complete occlusion 
Park et al.: Safety and Efficacy of Low-Profile, Self-Expandable Stents for Treatment of Intracranial Aneurysms: Initial and Midterm Results

Table 3. Comparison between LEO Baby and LVIS Jr stent

\begin{tabular}{|c|c|c|c|}
\hline Variables & LEO Baby & LVIS Jr & Total \\
\hline Number of IAs, $n(\%)$ of the total of 217 IAs & $128(59)$ & $89(41)$ & 217 \\
\hline SAH, $n(\%)$ of the total of 217 IAs & $18(14)$ & $30(33.7)$ & $48(22.1)$ \\
\hline Vessel diameter on stenting (range), mm & $0.75-3.1$ & $1.1-3.2$ & $0.75-3.2$ \\
\hline \multicolumn{4}{|l|}{ Location } \\
\hline Anterior circulation & $112(87.5)$ & $73(82)$ & $185(85)$ \\
\hline Posterior circulation & $16(12.5)$ & $16(18)$ & $32(15)$ \\
\hline \multicolumn{4}{|l|}{ Method of stent deployment } \\
\hline Single stent & $93(73)$ & $64(72)$ & $157(72)$ \\
\hline Overlapping & $22(17)$ & $20(22)$ & 42 (19) \\
\hline Balloon followed by stenting & $8(6)$ & $4(4)$ & $12(6)$ \\
\hline Flow diverter & 5 (1: blister) (4) & $1(1)$ & $6(3)$ \\
\hline \multicolumn{4}{|l|}{ Degree of obliteration } \\
\hline \multicolumn{4}{|l|}{ Immediately } \\
\hline I + II & $119(93)$ & $70(79)$ & $189(87)$ \\
\hline III & $7(7)^{a}$ & $19(21)^{\mathrm{b}}$ & $28(13)$ \\
\hline \multicolumn{4}{|l|}{ 3- to 6-month follow-up } \\
\hline $\mathrm{I}+\mathrm{II}$ & $119(93)$ & $40(44.9)$ & $159(73)$ \\
\hline III & $3(2)$ & $3(3.4)$ & $6(3)$ \\
\hline Stable & $-(-)$ & $34(38.2)^{c}$ & $34(6)$ \\
\hline No image on follow-up & $6(5)$ & $12(13.5)$ & $18(8)$ \\
\hline Recurrence of total number & $7(5)$ & $1(1)$ & $8(4)$ \\
\hline Recurrence of followed up number & 7 (5.7) & $1(1.3)$ & $8(6.5)$ \\
\hline Intraprocedural complications & $14(10.9)$ & $10(11.2)$ & $27(12.4)$ \\
\hline Thromboembolism & $8(6.3)$ & $6(6.7)$ & $14(6.5)$ \\
\hline Technical problem & $6(4.7)$ & $4(4.5)^{d}$ & $10(4.6)$ \\
\hline In-stent stenosis of total number & $15(11.7)$ & $4(4.2)$ & $19(9)$ \\
\hline In-stent stenosis of followed up number & $15(12.2)$ & $4(5.2)$ & $19(10)$ \\
\hline \multicolumn{4}{|l|}{ Clinical outcome } \\
\hline Good mRS score & $123(96)$ & $76(85)$ & $199(92)$ \\
\hline Procedure-related morbidity & $3(2)$ & $1(1)$ & $4(2)$ \\
\hline
\end{tabular}

Values are $n(\%)$ unless specified otherwise. IA, intracranial aneurysm; SAH, subarachnoid hemorrhage; mRS, modified Rankin Scale. ${ }^{a}$ Two IAs were not reported with immediate obliteration data due to thromboembolic events intraprocedurally [6]. ${ }^{b}$ Two patients were treated with flow diverters in the study by Akmangit et al. [9]. ${ }^{\mathrm{c}}$ Two studies reported stable results $[12,13] .{ }^{\mathrm{d}}$ Four cases in 1 publication (Möhlenbruch et al. [6]).

at 6 months. The rate of in-stent stenosis was higher with LEO Baby stents than with LVIS Jr stents. The rate of in-stent stenosis in the total of 217 IAs was $9 \%$ (11.7\% with LEO Baby stents and $4.2 \%$ with LVIS Jr stents), and the rate of in-stent stenosis in the 189 IAs which excluded the loss-to-follow-up data was 10\% (12.2\% with LEO Baby stents and 5.2\% with LVIS Jr stents). Procedure-related morbidity associated with LEO Baby stents and LVIS Jr stents was found in 2.4 and $1.1 \%$ of the cases, respectively.

\section{Meta-Analysis}

Seven studies were used for the meta-analysis, and the subgroup analysis was performed according to type of stent (LEO Baby vs. LVIS Jr). We conducted 3 meta-analyses by 3 outcomes: obliteration at 6 months, periprocedural complications, and technical complications (Fig. 2). Regarding obliteration at 6 months (Fig. 2a), the overall rates for the LEO Baby and the LVIS Jr stent were $0.86\left(95 \% \mathrm{CI} 0.80-0.92, I^{2} 0 \%\right)$ and 0.75 (95\% CI 0.66-0.84, $\left.I^{2} 0 \%\right)$, respectively. The analysis detected zero heterogeneity $(Q=1.6, p=0.449$, and $Q=1.3, p=0.732)$ and there 
Park et al.: Safety and Efficacy of Low-Profile, Self-Expandable Stents for Treatment of Intracranial Aneurysms: Initial and Midterm Results

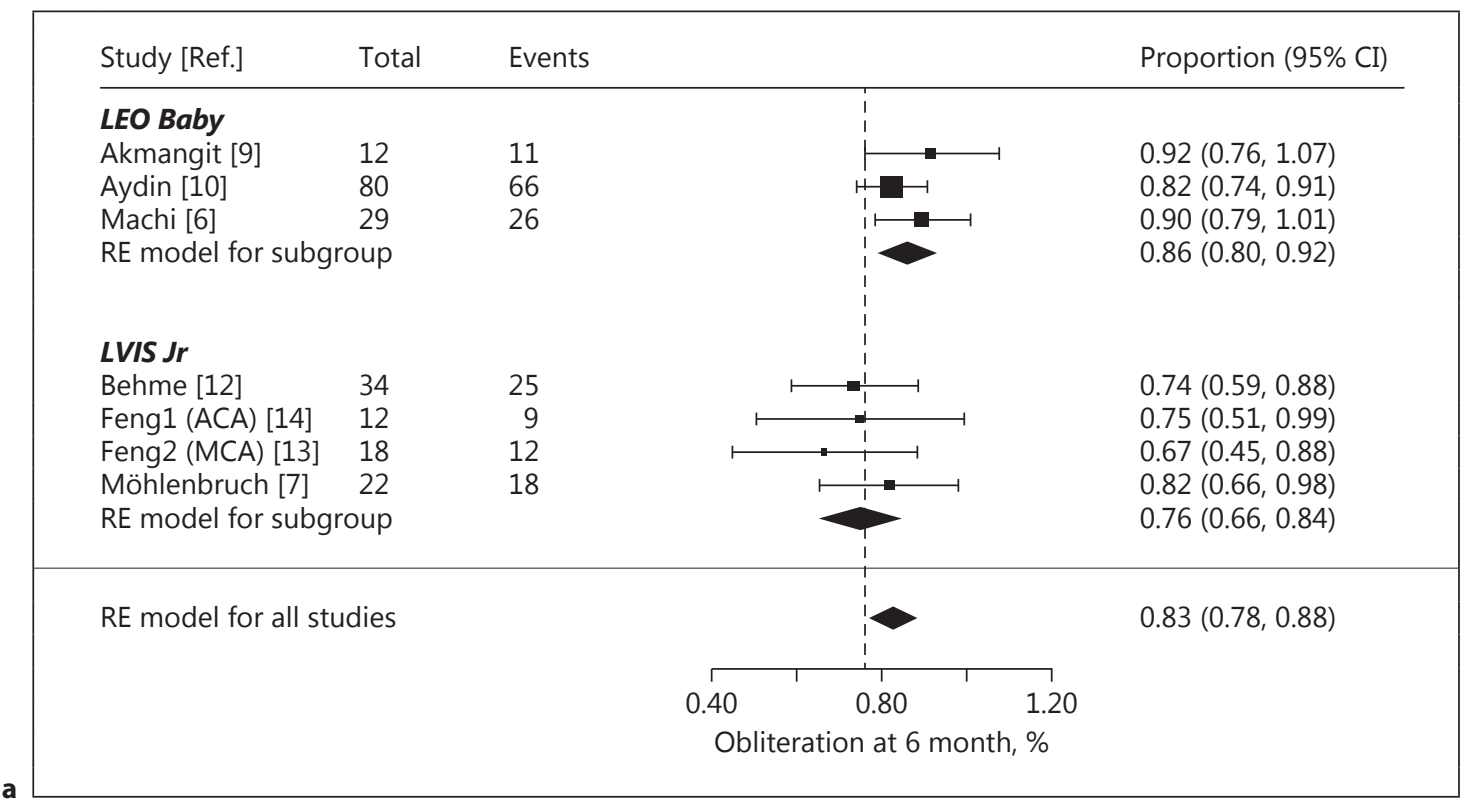

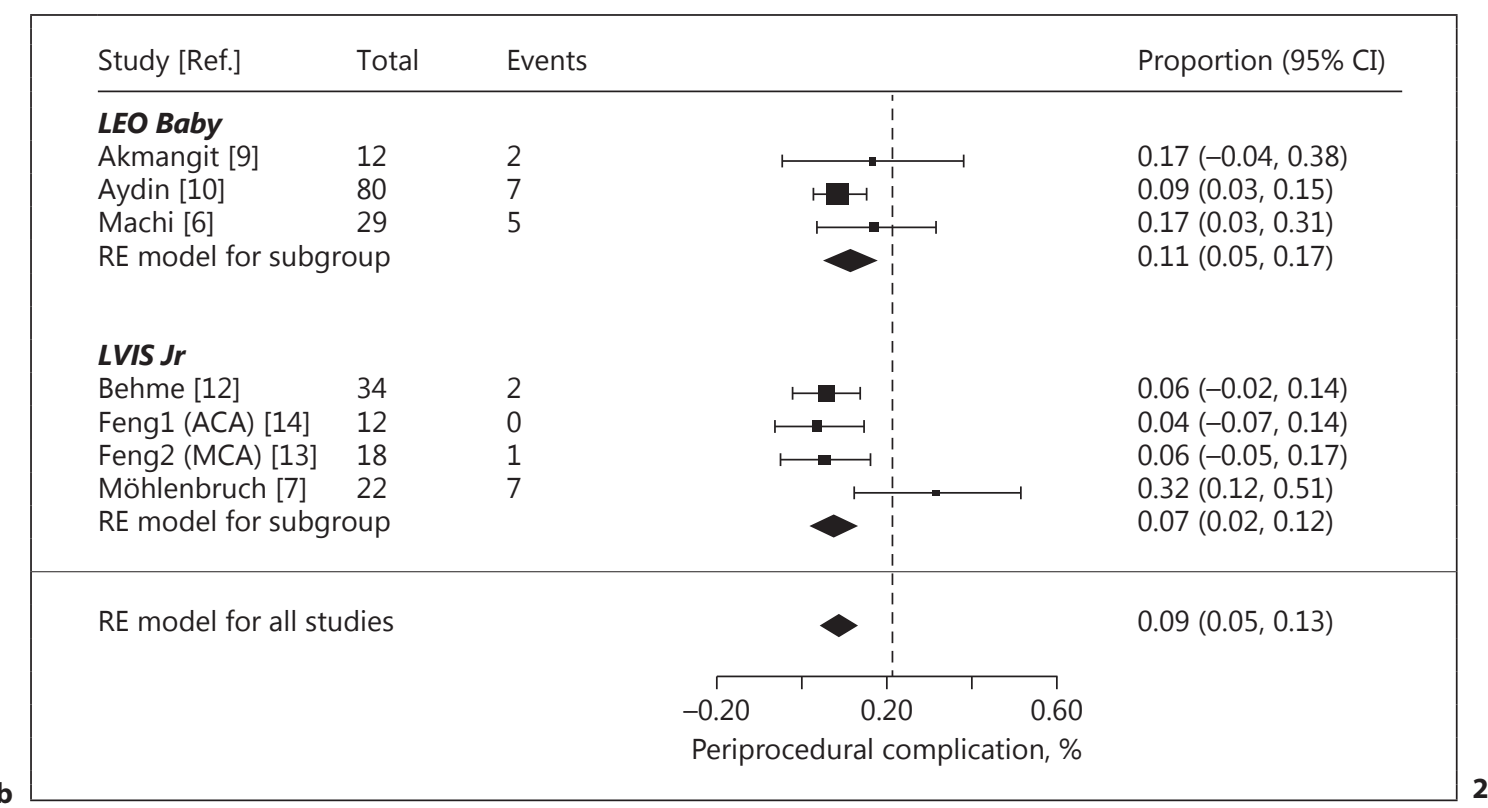

(Figure continued on next page.)

was no publication bias ( $p=0.315$ ). Regarding periprocedural complications (Fig. 2b), the overall complication rates for the LEO Baby and the LVIS Jr stent were 0.11 (95\% CI 0.05$\left.0.017, I^{2} 8.7 \%\right)$ and $0.09\left(95 \%\right.$ CI $\left.0.05-0.13, I^{2} 0.2 \%\right)$, respectively. The analysis detected low heterogeneity $(Q=1.6, p=0.459$, and $Q=6.7, p=0.081)$. Egger's test did not show any publication bias ( $p=0.112$ ). Regarding technical complications (Fig. 2c), the overall complication rates for the LEO Baby and the LVIS Jr stent were 0.04 (95\% CI $0.00-0.08, I^{2} 12.5 \%$ ) and 0.03 (95\% CI -0.01 to $\left.0.06, I^{2} 1 \%\right)$, respectively. The analysis detected low heterogeneity $(Q=2.3$, $p=0.311$, and $Q=4.0, p=0.263)$ and the result of Egger's test showed a publication bias ( $p=$ $0.013)$.

We conducted a post hoc analysis of noninferiority to show that LVIS Jr was not worse than LEO Baby regarding each of the outcomes. First of all, the difference between LVIS Jr and 
Park et al.: Safety and Efficacy of Low-Profile, Self-Expandable Stents for Treatment of Intracranial Aneurysms: Initial and Midterm Results

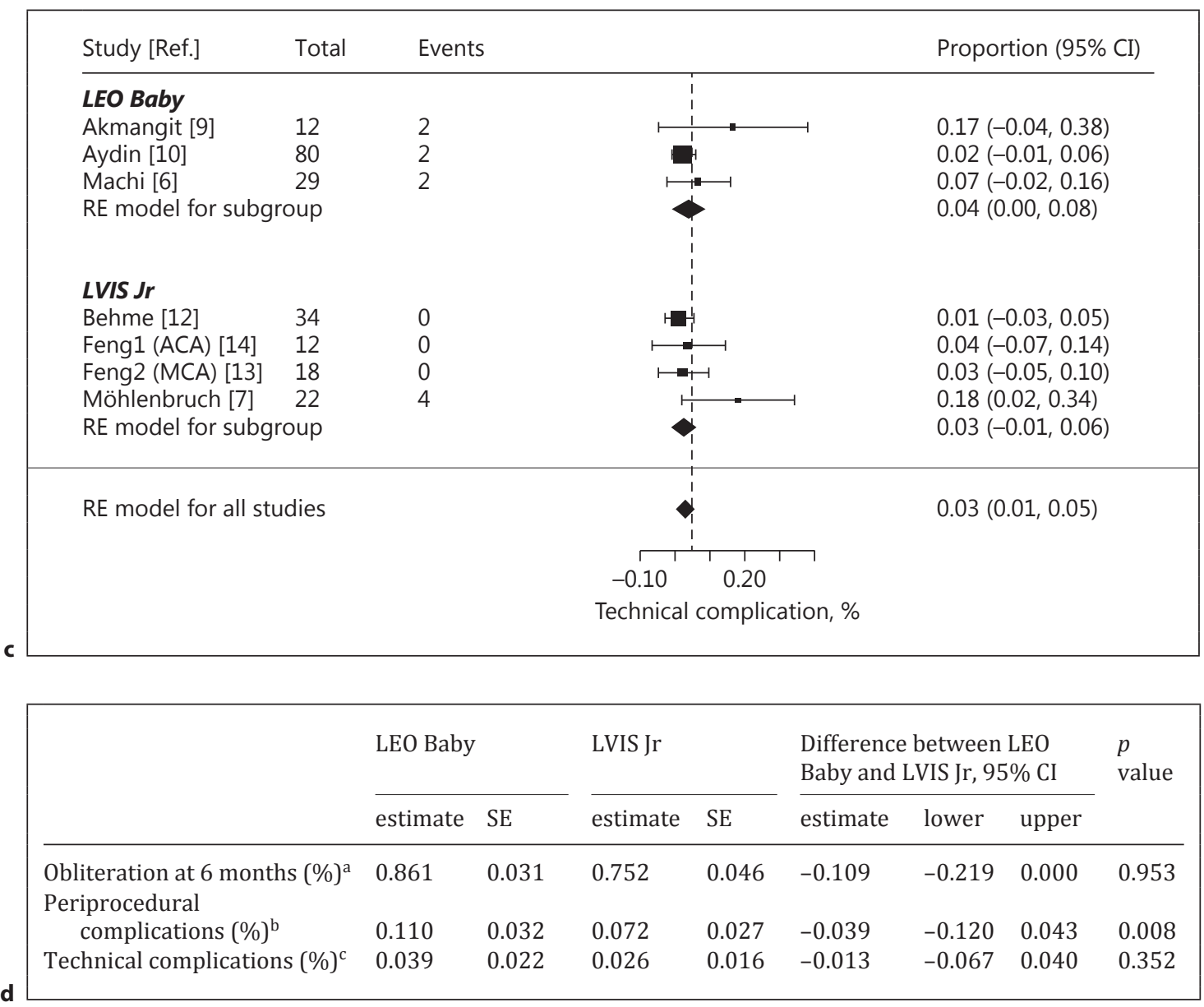

Fig. 2. Forest plots for aneurysmal obliteration at 6 months (a), periprocedural complications (b), and technical complications (c), and statistical results for the LEO Baby and LVIS Jr stents (d). RE model, randomeffects model. a Noninferiority was defined as a lower limit of the 95\% 1-sided confidence interval greater than $-0.1{ }^{\mathrm{b}}$ Noninferiority was defined as a lower limit of the $95 \% 1$-sided confidence interval $<0.1$. ${ }^{\mathrm{c}}$ Noninferiority was defined as a lower limit of the $95 \% 1$-sided confidence interval $<0.01$.

LEO Baby in obliteration rates at 6 months was not significant ( $p=0.953)$ and the $95 \%$ CI did not show noninferiority, because the lower limit of the $95 \% \mathrm{CI}$ was less than -0.1 (NI margin) and the upper limit of the $95 \% \mathrm{CI}$ was below zero. Second, the difference in rates of periprocedural complications was statistically significant $(p=0.008)$, and LVIS Jr also can be considered noninferior to LEO Baby, since the upper limit of the $95 \% \mathrm{CI}$ was less than 0.1 (NI margin) and the lower limit of the 95\% CI was less than zero. However, regarding technical complications there was no significant difference between the 2 groups $(p=0.352)$ and the result of the noninferiority test showed that LVIS Jr was simultaneously "noninferior" and "inferior" when 0.01 was the NI margin (estimate $-0.013,95 \%$ CI -0.067 to 0.040 ).

In summary, regarding obliteration rates at 6 months there was no significant difference between the 2 groups. However, the periprocedural complication rate with the LVIS Jr stent was significantly lower than that with the LEO Baby stent. 


\section{Discussion}

\section{LEO Baby Stent (Balt Extrusion, Montmorency, France)}

The LEO Baby stent is composed of braided mesh nitinol wires and has a sliding-strut design. It is composed of 16 wires and 2 platinum wires that permit its radiographic visualization. This design provides the benefits of good wall apposition, a tight mesh, and a relatively high radial force. The LEO Baby stent is resheathable up to approximately $95 \%$ of its deployment length and can be repositioned. It has a relatively small cell size $(0.9 \mathrm{~mm})$ and is available in diameters of 2.0 and $2.5 \mathrm{~mm}$ and lengths of $12,18,25,30$, and $35 \mathrm{~mm}$ [7]. It is recommended to deploy this stent in arteries with diameters between 1.5 and $3.2 \mathrm{~mm}$. This is the only self-expandable stent that can be deployed in arteries with a diameter below $2 \mathrm{~mm}$. Cohen et al. [11] reported that LEO Baby stents measuring 0.75-2.1 mm were deployed in A1 and A2 arteries which presented an acute angle using the X-stenting method. Aydin et al. [10] reported that successful deployment was obtained in arteries with diameters as small as 1.3 $\mathrm{mm}$, and successful Y-stenting was achieved with a small microcatheter (internal diameter 1.7 Fr). In addition, the LEO Baby stent has shorter flared ends, which can ease reentry of the stent for navigation of the microcatheter or for dual stent placement, and it has a higher radial force. The LEO Baby stent has received the CE mark for use in the EU, but it has not received approval from the Food and Drug Administration (FDA).

\section{LVIS Jr Stent (MicroVention-Terumo, Tustin, CA, USA)}

The LVIS Jr (Low-Profile Visualized Intraluminal Support Junior) device is a self-expanding nitinol single-wire braid device with 3 radiopaque tantalum threads within the body of the stent and radiopaque markers in the proximal and distal ends. Its surface area coverage is $12-21 \%$. It is recommended to deploy the LVIS Jr stent through a 0.017 -inch luminal microcatheter which can also be used for coil deployment, and to deploy it in arteries with diameters of 2.0-3.5 $\mathrm{mm}$, as the fully expanded diameter of the device is $3.5 \mathrm{~mm}$. A Scepter C or XC balloon catheter (MicroVention) could allow delivery of the LVIS Jr stent. Although it is recommended to use the LVIS Jr device for a parent vessel size measuring up to a maximum of $3.5 \mathrm{~mm}$, Behme et al. [12] reported that successful deployment in the proximal landing zone was obtained with a maximal diameter of $5.0 \mathrm{~mm}$. The LVIS Jr stent was foreshortened to increase the diameter size in order to accommodate the parent vessel size. This is an advantage of a braided stent compared with a laser-cut stent. The LVIS Jr stent is a compliant, closed stent which is resheathable up to approximately $80 \%$ of its deployment length and can be repositioned. It has a relatively large cell size $(1.5 \mathrm{~mm})$ compared with the LVIS stent $(1.0 \mathrm{~mm})$ or the LEO Baby stent $(0.9 \mathrm{~mm})$. Therefore, application of the stent-through technique may be possible with this stent.

The LVIS Jr stent makes an angle between the afferent vessels and the efferent vessels of the aneurysm before stenting on the anterior cerebral artery and the MCA, and the angle increases after stenting. The angle was significantly increased to 20.3 and $27.6 \%$ on the anterior cerebral artery and MCA, respectively $[13,14]$. This implies that it has adequate radial force for bail-out stenting.

\section{Obliteration Rates and Recurrence Rates}

Rates of successful obliteration (I or II) on immediate angiographic results using Solitaire AB (Medtronic), Neuroform (Stryker Neurovascular, Fremont, CA, USA), and Enterprise (Codman) stents were approximately 81,87 , and $77 \%$, respectively [15-17]. Compared with these studies, low-profile, self-expandable stents provided similar obliteration results in 93 and $73 \%$ of the aneurysms using LEO Baby and LVIS Jr stents, respectively, according to our systematic review. Also, recurrence rates after using the Enterprise and the Neuroform stent were $19.3 \%$ at 6 months and $9.7 \%$ at $12-18$ months, respectively $[15,17]$. However, usage of 
low-profile, self-expandable stents was associated with a relatively low recurrence rate as compared with other stents. The recurrence rate after using low-profile stents was $6.5 \%$ (5.7\% with LEO Baby stents and 1.3\% with LVIS Jr stents). Use of the LVIS Jr stent is associated with a very low recurrence rate, and it seems to have stronger flow diverter effects than other stents. Low-profile, self-expandable stents seem to have the capability of changing the aneurysmal flow like a pipeline due to higher metal coverage. In the meta-analysis of selected publications, there was no significant difference in obliteration at 6 months between the 2 groups of LEO Baby and LVIS Jr reports.

\section{Complication Rates}

Application of the LEO Baby and the LVIS Jr stent resulted in a similar rate of periprocedural complications (thromboembolism) according to our systematic review. The rate of in-stent stenosis with the LVIS Jr stent was relatively lower than that with the LEO Baby stent. However, the periprocedural complication rate with LVIS Jr was significantly lower than that with LEO Baby in the meta-analysis of selected publications.

Although a study on the Solitaire stent showed a low proportion of cases with subarachnoid hemorrhage (SAH) (7.9\%), the incidence of periprocedural thromboembolism was high $(12.5 \%)$ [16]. A study on the Enterprise stent showed a relatively low incidence of periprocedural thromboembolism (3.2\%) despite a high proportion of SAH patients (42\%) [17].

The rate of technical complications was low with the Enterprise and Solitaire AB stents ( $0 \%$ with the Enterprise stent and $1.5 \%$ with the Solitaire AB stent) compared with those in our study and with the Neuroform stent $(6.5 \%$ with a low-profile stent and $3.7 \%$ with the Neuroform stent). Although low-profile, self-expandable stents do not have to be navigated to the parent artery by the exchange technique, it seems to be technically difficult to deploy them, because they are usually deployed on small or tortuous parent arteries. We thought that partial stent opening or migration of a low-profile, self-expandable stent is due to its relatively low radial force compared with that of other stents.

\section{Limitations}

First, this study did not include a randomized control group, and most studies included only a small number of cases. However, low-profile stents for IAs have recently been used, and most of the centers which performed studies on them seemed to have greater neuroendovascular experience. Second, in this study $22 \%$ of the 217 IAs were ruptured. SAH is known to increase the risk of thromboembolic events during SAC. If the proportion of patients with SAH increases, the number of thromboembolic events might increase as well. This issue needs to be evaluated through further study. Third, low-profile, self-expandable stents have been used since 2011. Although the rates of recurrence and in-stent stenosis with the LVIS Jr stent were lower than with other self-expandable stents, long-term follow-up and a higher number of cases are needed.

\section{Conclusion}

A low-profile, self-expandable stent is a safe and useful device for IAs because it has the advantage of deployment in a smaller parent artery and higher metal coverage. As a midterm result, the recurrence rate was relatively low compared to that with other self-expandable stents. However, it is associated with a relatively high rate of periprocedural thromboembolism and technical complications. In our meta-analysis, the LVIS Jr stent seemed to have a relatively low rate of periprocedural complications. 
Park et al.: Safety and Efficacy of Low-Profile, Self-Expandable Stents for Treatment of Intracranial Aneurysms: Initial and Midterm Results

\section{Acknowledgments}

This research was supported by the Soonchunhyang University Research Fund.

\section{Statement of Ethics}

For this type of study, formal consent is not required, since this study was performed retrospectively. Informed consent was obtained from all individual participants included in the study.

\section{Disclosure Statement}

All authors certify that they have no affiliations with or involvement in any organization or entity with any financial interest (such as honoraria; educational grants; participation in speakers' bureaus; membership, employment, consultancies, stock ownership, or other equity interest; and expert testimony or patentlicensing arrangements) or nonfinancial interest (such as personal or professional relationships, affiliations, knowledge, or beliefs) in the subject matter or materials discussed in this manuscript.

\section{References}

1 Akpek S, Arat A, Morsi H, Klucznick RP, Strother CM, Mawad ME: Self-expandable stent-assisted coiling of wide-necked intracranial aneurysms: a single-center experience. AJNR Am J Neuroradiol 2005;26:12231231.

2 Piotin M, Blanc R, Spelle L, Mounayer C, Piantino R, Schmidt PJ, Moret J: Stent-assisted coiling of intracranial aneurysms: clinical and angiographic results in 216 consecutive aneurysms. Stroke 2010;41:110-115.

3 Mascitelli JR, Moyle H, Oermann EK, Polykarpou MF, Patel AA, Doshi AH, Gologorsky Y, Bederson JB, Patel AB: An update to the Raymond-Roy Occlusion Classification of intracranial aneurysms treated with coil embolization. J Neurointerv Surg 2015;7:496-502.

4 DerSimonian R, Laird N: Meta-analysis in clinical trials. Control Clin Trials 1986;7:177-188.

5 Higgins JP, Thompson SG, Deeks JJ, Altman DG: Measuring inconsistency in meta-analyses. BMJ 2003;327: 557-560.

6 Machi P, Costalat V, Lobotesis K, Ruiz C, Cheikh YB, Eker O, Gascou G, Danière F, Riquelme C, Bonafé A: LEO Baby stent use following balloon-assisted coiling: single- and dual-stent technique - immediate and midterm results of 29 consecutive patients. AJNR Am J Neuroradiol 2015;36:2096-2103.

7 Möhlenbruch M, Herweh C, Behrens L, Jestaedt L, Amiri H, Ringleb PA, Bendszus M, Pham M: The LVIS Jr microstent to assist coil embolization of wide-neck intracranial aneurysms: clinical study to assess safety and efficacy. Neuroradiology 2014;56:389-395.

8 Dall'olio M, Calbucci F, Fioravanti A, Bortolotti C, Cirillo L, Princiotta C, Leonardi M: Revascularized giant aneurysm of the anterior communicating artery after surgery and embolization, occluded by placement of a Leo+Baby intracranial stent. Neuroradiol J 2013;26:320-326.

9 Akmangit I, Aydin K, Sencer S, Topcuoglu OM, Topcuoglu ED, Daglioglu E, Barburoglu M, Arat A: Dual stenting using low-profile LEO Baby stents for the endovascular management of challenging intracranial aneurysms. AJNR Am J Neuroradiol 2015;36:323-329.

10 Aydin K, Arat A, Sencer S, Barburoglu M, Men S: Stent-assisted coiling of wide-neck intracranial aneurysms using low-profile LEO Baby stents: initial and midterm results. AJNR Am J Neuroradiol 2015;36:1934-1941.

11 Cohen JE, Melamed I, Itshayek E: X-microstenting and transmesh coiling in the management of wide-necked tent-like anterior communicating artery aneurysms. J Clin Neurosci 2014;21:664-667.

12 Behme D, Weber A, Kowoll A, Berlis A, Burke TH, Weber W: Low-Profile Visualized Intraluminal Support device (LVIS Jr) as a novel tool in the treatment of wide-necked intracranial aneurysms: initial experience in 32 cases. J Neurointerv Surg 2015;7:281-285.

13 Feng Z, Li Q, Zhao R, Zhang P, Chen L, Xu Y, Hong B, Zhao W, Liu J, Huang Q: Endovascular treatment of middle cerebral artery aneurysm with the LVIS Junior stent. J Stroke Cerebrovasc Dis 2015;24:1357-1362.

14 Feng Z, Zhang L, Li Q, Zhao R, Xu Y, Hong B, Zhao W, Liu J, Huang Q: Endovascular treatment of wide-neck anterior communicating artery aneurysms using the LVIS Junior stent. J Clin Neurosci 2015;22:1288-1291.

15 Gentric JC, Biondi A, Piotin M, Mounayer C, Lobotesis K, Bonafé A, Costalat V; French SENAT Investigators: Safety and efficacy of Neuroform for treatment of intracranial aneurysms: a prospective, consecutive, French multicentric study. AJNR Am J Neuroradiol 2013;34:1203-1208. 
Park et al:: Safety and Efficacy of Low-Profile, Self-Expandable Stents for Treatment of Intracranial Aneurysms: Initial and Midterm Results

16 Gory B, Klisch J, Bonafé A, Mounayer C, Beaujeux R, Moret J, Lubicz B, Riva R, Turjman F: Solitaire AB stentassisted coiling of wide-necked intracranial aneurysms: short-term results from a prospective, consecutive, European multicentric study. Neuroradiology 2013;55:1373-1378.

17 Weber W, Bendszus M, Kis B, Boulanger T, Solymosi L, Kühne D: A new self-expanding nitinol stent (Enterprise) for the treatment of wide-necked intracranial aneurysms: initial clinical and angiographic results in 31 aneurysms. Neuroradiology 2007;49:555-561.

18 Conrad MD, Brasiliense LBC, Richie AN, Hanel RA: Y stenting assisted coiling using a new low profile visible intraluminal support device for wide necked basilar tip aneurysms: a technical report. J Neurointerv Surg 2014;6:296-300.

19 Negrotto M, Crosa R, Casagrande W: Assisted coiling using LEO Baby or LVIS Jr stents: report of six cases. Interv Neuroradiol 2015;21:566-574. 